\title{
Covalent immobilization of glucoamylase enzyme onto chemically activated surface of K-carrageenan
}

\author{
Mohamed E. Hassan ${ }^{1,2^{*}}$ D, Qingyu Yang ${ }^{1}$ and Zhigang Xiao ${ }^{1 *}$
}

\begin{abstract}
Background: Glucoamylase enzyme is one of the most important enzymes. It catalyzes the hydrolysis of starch into soluble sugars. It was covalently immobilized onto $\mathrm{k}$-carrageenan gel beads after activation by using polyethylenimine (PEI) followed by glutaraldehyde (GA). All parameters in activation process were studied.

Results: The immobilized enzyme shows enhancement in temperature profile as the optimum temperature for the free enzyme was $60^{\circ} \mathrm{C}$, and it becomes $60-80^{\circ} \mathrm{C}$ that means broader range and also shows stability in acidic conditions more than free enzyme. The apparent Km of immobilized enzyme, $147.46 \mathrm{mM}$, becomes higher than $\mathrm{Km}$ of the free one, $110 \mathrm{mM}$ and the maximum reaction velocity (Vmax) values for the immobilized enzyme decreased from 2.28 to $1.11 \mu \mathrm{mol} \mathrm{min}{ }^{-1}$. The immobilized enzyme can be reused and kept its activity (100\%) till 11 successive cycles. The immobilization process steps were characterized by FTIR and SEM.

Conclusions: These results confirm the economic and biotechnical benefits of enzyme immobilization, particularly with regard to the number of enzyme reuses, which open the possibility of different industrial applications.
\end{abstract}

Keywords: Glucoamylase, Covalent immobilization, Beads activation, Reusability

\section{Introduction}

One of the great importance to food industries, fermentation, and scarification of most oligosaccharides and starch is glucoamylase enzyme ( $\alpha$-1, 4-glucan glucohydrolase, amyloglucosidase, EC 3.2.1.3). This enzyme can hydrolyze glycosidic bonds $(\alpha-1,4)$ found in starch in the production of glucose (Wang et al. 2012). There are a lot of microorganisms which can produce this enzyme (glucoamylase), the microorganisms which can be classified as industrial organisms such as Aspergillus niger, Aspergillus awamori, and Rhizopus oryzae (Coutinho and Reilly 1997).

In various production stages, enzymatic bioconversion processes have been widely used. This process, the enzymatic one, has many advantages; the most important advantage is that it is not dangerous for the environment as it is a cleaner technology (Faber, 2011). Enzyme reactions also save time and have a high degree of substrate specificity (Bassem et al. 2018). But it cannot be separated from the

\footnotetext{
*Correspondence: mohassan81@gmail.com; zhigangx@sina.com ${ }^{1}$ College of Grain Science and Technology, Shenyang Normal University, 253 Huanghe North Street, Huanggu District, Shenyang 110034, China Full list of author information is available at the end of the article
}

reaction easily (Mohamed et al. 2019). This problem can be solved by immobilization of the enzyme on a solid support (Girelli and Mattei, 2005).

Immobilized enzymes are used in many industries such as food technology, analytical chemistry, biomedicine, and biotechnology. They have various advantages over free enzymes, as it improves thermal stability and increases resistance to $\mathrm{pH}$ changes of the reaction (Sunita, 2019). It also provides reuse ability for enzymes which makes the reaction cost decrease because of the easy recovery of the immobilized enzyme. To achieve this, enzymes can be immobilized in or on the surface of different carriers by using different methods such as adsorption, entrapment, ionic bonding, and covalent binding (Alftrén and Hobley, 2013). The very effective method is the covalent binding method (Schultz et al. 2007). By using this method, the enzyme can be retained and also can achieve high activity after immobilization because of the strong interaction between the enzyme function group and support material (Gerhartz, 1990).

There is a rapid progress in studies on glucoamylase immobilization; many supports have been used. These 
include ceramic membranes (Ida et al. 2000), polymer microspheres (Oh and Kim, 2000), magnetic supports (Wang et al. 2014).

For choosing a support material for enzyme immobilization, the carrier, which is a support material, should have some features such as good mechanical strength and large surface area containing available function groups, should be resistant for microbial attachment, and finally should be cheap in production. All of these features are found in $\mathrm{k}$-carrageenan (Bezerra et al. 2015).

Among immobilization techniques, we used the covalent one as it contains the formation of covalent bond, strong bond, between enzyme function group and carrier function group (Franzreb et al. 2006).

In this work, glucoamylase has been immobilized onto treated $\mathrm{k}$-carrageenan gel beads with polyethylenimine and glutaraldehyde. Immobilized glucoamylase can provide many advantages for biotechnological and industrial applications; these advantages include reusability, ease of separation of products from the enzyme, improved enzyme stability at different temperature, and $\mathrm{pH}$ without changing enzyme properties. These factors have been studied in addition to the kinetic constants of immobilized and free glucoamylase. The steps for treating the hydrogel and immobilizing the enzyme were monitored using FTIR and SEM.

\section{Material and methods Materials}

к-Carrageenan, glucoamylase enzyme (100k units/mg solid lyophilized powder), and polyethylenimine (PEI) were purchased from Beijing Solarbio Co., Ltd; potassium chloride was purchased from Tianjin Kermel Chemical Reagent Co., Ltd; and glutaraldehyde (GA) (50\%) was from Shanghai Aladdin Biochemical Technology Co., Ltd. All other fine chemicals were of Analar or equivalent quality.

\section{Methods \\ Preparation of gel beads}

$\mathrm{K}$-Carrageenan was dissolved in distilled water to produce polymer solutions with a concentration of $2 \%(w /$ $v$ ); the solution was left standing to disengage bubble before use. Afterwards, we spray polymer solution of $\mathrm{k}$ carrageenan into $\mathrm{KCl}$ solution $2 \%(w / v)$ by using a syringe. The formed microcapsules were hardened in crosslinking solution for $3 \mathrm{~h}$. Then, the gel beads are ready for immobilization (Ying et al. 2016).

\section{Activation of gel beads}

Firstly, we soak the beads in amine solution of polyethyleneimine (PEI) for $3 \mathrm{~h}$ and then wash it well to remove excess PEI; we now put the beads in a glutaraldehyde (GA) solution for $3 \mathrm{~h}$, and then after, we wash it well to remove unbound GA. These beads were ready for immobilization
(Fig. 1). Here, we can notice that the beads' color becomes orange brown while it was translucent. This color appears because of the reaction between amino groups found in PEI and aldehyde group found in GA forming Schiff's base $(-\mathrm{N}=\mathrm{CH}-)$ (Elnashar et al. 2013).

\section{Covalent immobilization of glucoamylase onto the activated gel beads}

In this step, the enzyme amino group $\left(\mathrm{NH}_{2}\right)$ reacted with the free $\mathrm{C}=\mathrm{O}$ groups of glutaraldehyde that was found on the surface of activated gel beads forming amide bond $(\mathrm{C}=$ $\mathrm{N}-$ ) (Amal et al. 2016). About $1 \mathrm{~g}$ of the previously treated gel beads was loaded with $4 \mathrm{~mL}$ of $100 \mathrm{mM}$ acetate buffer ( $\mathrm{pH} 5$ ) containing $15 \mathrm{U}$ glucoamylase. This mixture was incubated in bottle $(25 \mathrm{~mL})$ for $16 \mathrm{~h}$ at room temperature using a roller stirrer, and then the gel beads were washed well with buffer and directly assayed for glucoamylase activity.

\section{Determination of glucoamylase activity}

Glucoamylase can transform starch into glucose so the determination of glucoamylase activity was done by using the dinitrosalicylic acid (DNS) method. Glucoamylase activity was measured by mixing $200 \mu \mathrm{L}$ free enzyme (or $0.5 \mathrm{~g}$ beads of immobilized enzyme) with $1 \mathrm{~mL}$ starch (5\% in acetate buffer $\mathrm{pH}$ ) and incubated it for $10 \mathrm{~min}$ at $50^{\circ} \mathrm{C}$. To stop the reaction, we add $2 \mathrm{~mL}$ of DNS and boil for 5 min and then cool to room temperature. Blank is $200 \mu \mathrm{L}$ buffer to $1 \mathrm{~mL}$ starch at the same conditions of the reaction and read with spectrophotometer at $\lambda 540 \mathrm{~nm}$. One unit of enzyme activity was equivalent to the amount of enzyme required to produce $1 \mu \mathrm{mol}$ glucose/min (Miller, 1959).

\section{Evaluation of the catalytic activity of glucoamylase Determination of optimum $\mathrm{pH}$}

Both free and immobilized glucoamylase were assayed in different values of buffer ( $\mathrm{pH} 3.5-8)$ as described in the section of determination of glucoamylase activity. The buffer used was $100 \mathrm{mM}$ acetate buffer. The activity measured at optimum $\mathrm{pH}$ was taken as the $100 \%$ activity, and the other activities at other $\mathrm{pH}$ values were expressed as a percentage of this optimum 100\% activity.

\section{Determination of optimum temperature}

Both free and immobilized glucoamylase were assayed at different temperatures $\left(30-90^{\circ} \mathrm{C}\right)$ as described in the section on the determination of glucoamylase activity. Activity at an optimum temperature was taken as the $100 \%$ activity, and the other activities at other temperatures were expressed as a percentage of this 100\% activity. 


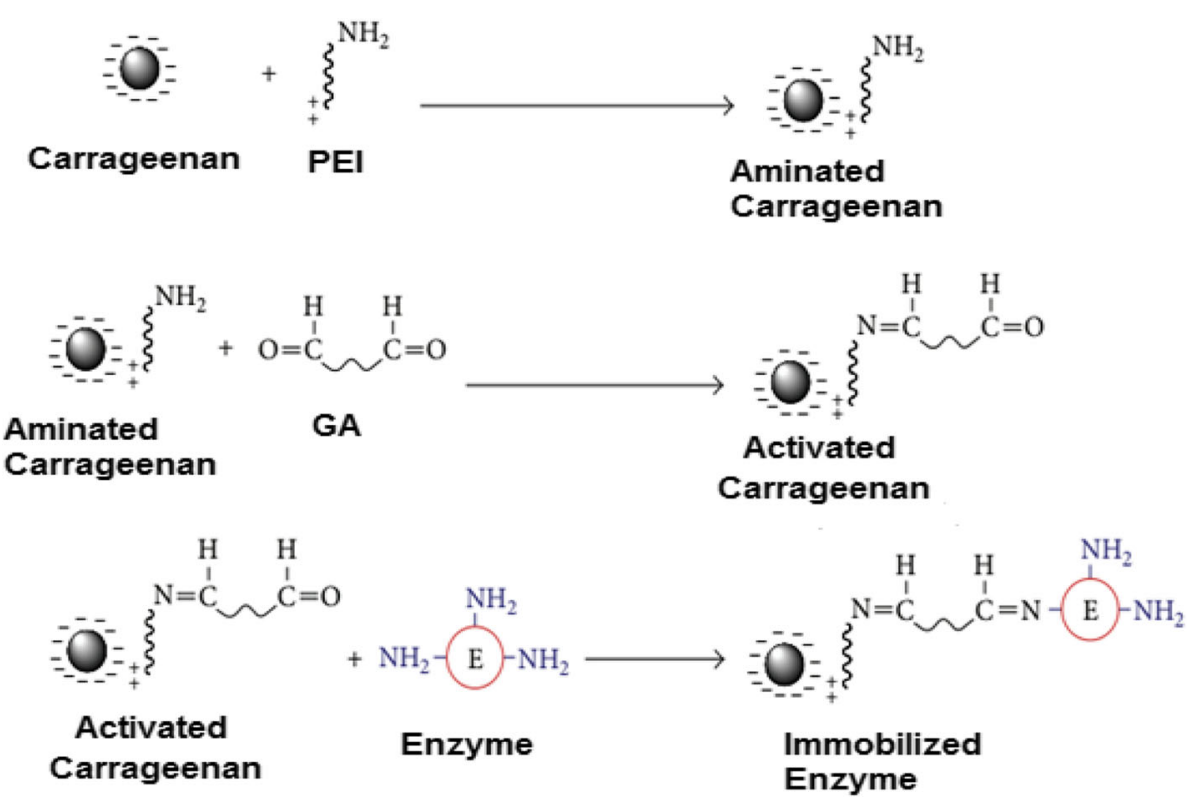

Fig. 1 Schematic representation of carrageenan gel beads activation and enzyme immobilization

Km and Vmax of immobilized and free glucoamylase

These parameters, Km and Vmax, for free and immobilized of glucoamylase were determined by using the HanesWoolf plot. To determine $\mathrm{Km}$ and Vmax, we used different final concentrations of starch $(25-300 \mathrm{mM})$ in $100 \mathrm{mM}$ acetate buffer of $\mathrm{pH} 5$.

\section{Operational stability (reusability)}

This is one of the most important characters for the immobilized enzyme, so immobilized glucoamylase on activated beads was used in glucose production from starch for many times and after each reaction, the beads containing enzyme were washed well by using a buffer and reassayed again and the initial activity was considered as $100 \%$. The relative activity was expressed as a percentage of the starting operational activity.

\section{Fourier-transform infrared (FTIR)}

Infrared spectra of all formulations were recorded with Fourier-transform infrared spectroscopy (FTIR-850, Tianjin Guangdong Sci \& Tech Development Co., Ltd, China). FTIR spectra were taken in the wavelength region from 400 to $4000 \mathrm{~cm}^{-1}$ at ambient temperature.

\section{Scanning electron microscope (SEM)}

The difference occurred in the surface of different formulations (carrageenan, aminated carrageenan, activated one, and enzyme immobilized on beads) was examined using a scanning electron microscope (SEM, SU3500, HITACHI) to prove the changes that happened in the gel beads' surface as a result of each reaction.
Statistical analysis Data were analyzed with Microsoft Excel 2007. Results were expressed as the mean \pm standard error.

\section{Results}

Gel beads' activation process

\section{Step A}

We optimized this step which deals with PEI while keeping conditions of the reaction for step B constant. In all the experiments, the gel beads were soaked in a solution of $0.5 \%(v / v)$ GA for $2 \mathrm{~h}$ at room temperature.

Effect of the PEI concentration The effect of the different concentrations of PEI on the catalytic activity of immobilized glucoamylase is shown in Fig. 2. It is clear that there was a linear increase in activity while increasing PEI concentration. This increase up to $1 \%$, and after that, concentration tends to stabilize. This increase in enzyme activity is due to the increase in amine groups on the surface of carrageenan gel beads that were related to the increase of PEI concentration.

Effect of PEI pH To determine the best PEI pH, 7 different $\mathrm{pH}$ values (from 7 and 10.5) were studied as shown in Fig. 3. The results displayed a linear increase in the amount of immobilized glucoamylase with the increase in values of PEI's pH up to 9, and there is a gradual decrease in the catalytic activity.

Effect of PEI reaction time It is evident in Fig. 4 that variation in reaction time of PEI has an effect on immobilized glucoamylase activity. The obtained results 


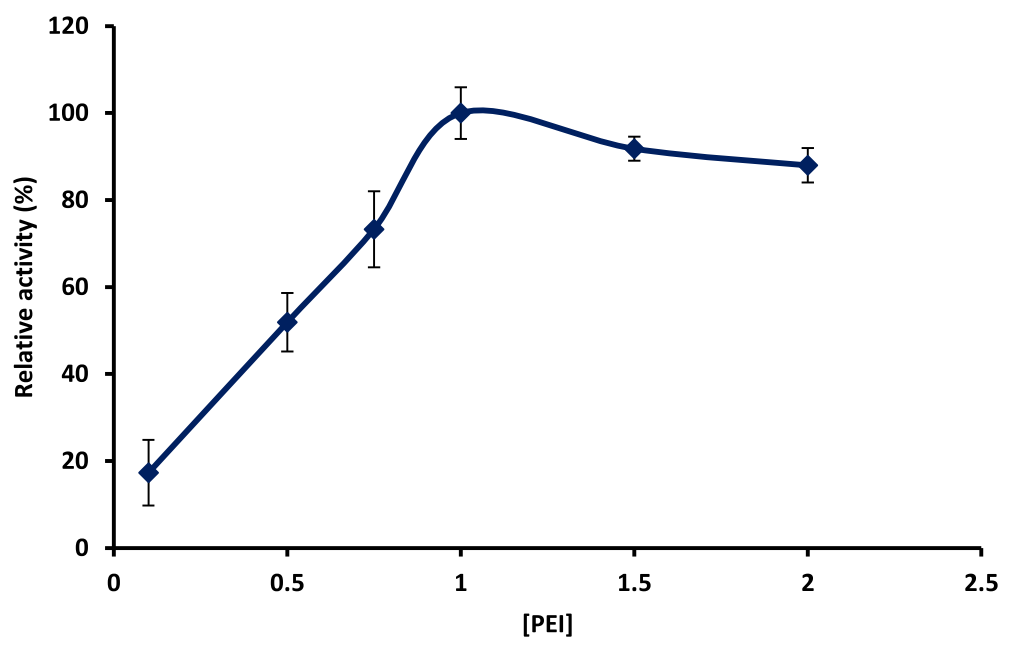

Fig. 2 Effect of variation of PEl concentration on the catalytic activity of immobilized enzyme

confirmed the given explanation concerning the reaction between the surfaces of the carrageenan beads with PEI. In general, the catalytic activity increases with the increase of reaction time with PEI up to $2 \mathrm{~h}$. The activity slightly decreased after $2 \mathrm{~h}$. This data was in agreement with that reported by Wahba and Hassan (2017).

\section{Step B}

Step B, activation process, which involved the determination of best condition needed for the reaction of GA with the PEI-treated gel beads. This activation step is for creating new free active aldehyde groups on the surface of gel beads capable of covalently immobilizing glucoamylase. Optimization of step B involves the determination of the optimum conditions of GA concentration and soaking time. The steps done during the optimizations of step A were employed here.

Effect of GA concentration The effect of the different concentrations of GA on immobilized glucoamylase activity was investigated. Figure 5 reveals that with increasing GA concentration up to $0.5 \%$, there is a linear increment of the activity was observed. It was expected that with the increasing of GA concentrations, the amount of immobilized enzyme will increase dramatically, but further increasing of GA concentration to $4 \%$ $(v / v)$ caused a decrease in the amount of immobilized glucoamylase slightly.

Effect of GA soaking time To determine the best time for the reaction between activated beads and GA, seven different times of soaking beads in GA ranging from 0.5 to $5 \mathrm{~h}$ were studied. The activity of immobilized glucoamylase varied slightly along with the entire tested time range. Figure 6 describes this effect. The obtained data show that during the increasing reaction time with GA up to $3 \mathrm{~h}$, the activity of the immobilized enzyme increases and, after that, the activity tends to decrease, so the best time is $3 \mathrm{~h}$.

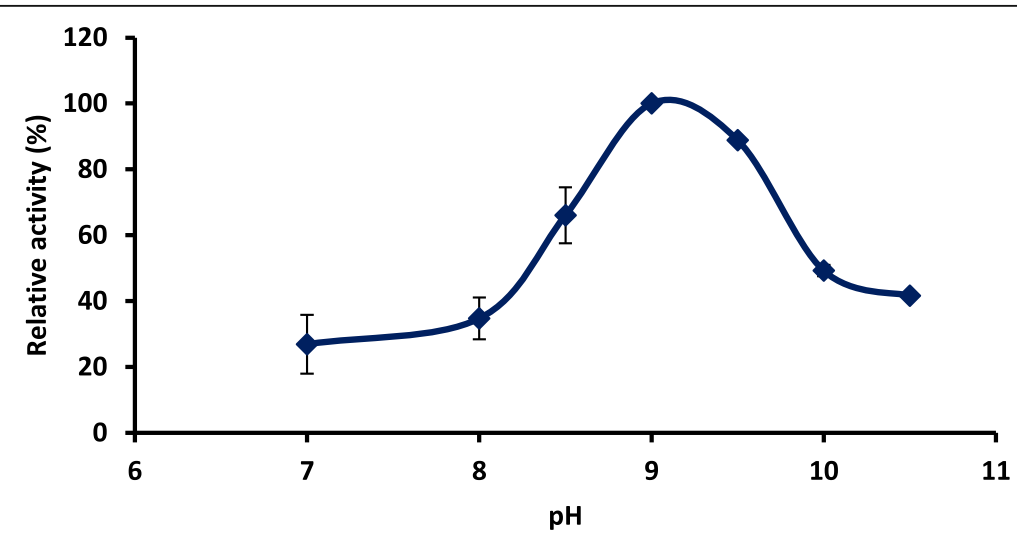

Fig. 3 Effect of variation of PEl pH on the catalytic activity of immobilized enzyme. 


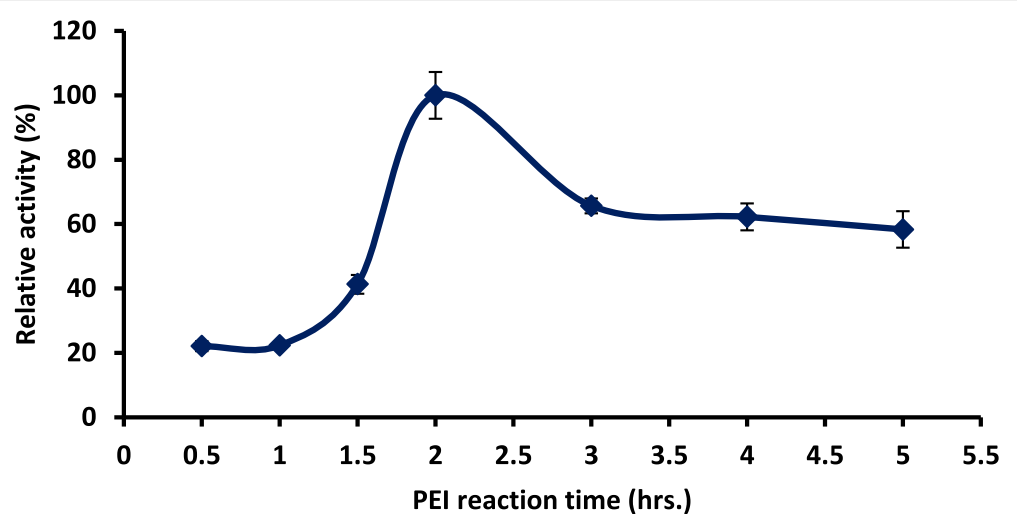

Fig. 4 Effect of variation of PEl reaction time on the catalytic activity of immobilized enzyme

\section{Evaluation of catalytic activity of free and immobilized glucoamylase}

At this stage, we studied five important experiments. They were divided into two sections: in the first one, we determined the optimum values of $\mathrm{pH}$, temperature, and substrate concentration. Then, we used these data to determine the full conversion rate of the substrate and immobilized enzyme reusability.

\section{Optimum $\mathrm{pH}$}

In this experiment, we measured enzymatic activity for free and immobilized enzyme using different substrate $\mathrm{pH}$ values. Figure 7 shows the activity behavior of both free and immobilized glucoamylase. Although there is no big difference between the optimum $\mathrm{pH}$ values for two forms of enzyme, we can notice that the $\mathrm{pH}$ values of immobilized one became slightly broader than those of free. This result shows that the immobilized glucoamylase became more stable for changes in $\mathrm{pH}$ than the free one.

\section{Optimum temperature}

Figure 8 shows the free and immobilized enzyme temperature profile. In studying the enzymatic activity in different substrate's temperature, a bell-shaped curve is obtained. From that curve, we can see that the curve of immobilized enzyme became wider and broader than that of the free one, although the optimum temperature is the same in the case of free and immobilized enzyme. Also, there are very interesting observations from a close inspection of that figure; one of them is the wide range of temperature $\left(20^{\circ} \mathrm{C}\right)$; during this range, the immobilized glucoamylase can keep $96-100 \%$ of its initial activity. It should be noted here that the effect of environmental temperature on the immobilized enzyme is less than the free one.

\section{Kinetic parameters}

The kinetic parameters of free and immobilized glucoamylase were shown in Fig. 9. The apparent $\mathrm{Km}$ of the immobilized enzyme, $147.46 \mathrm{mM}$, become higher than the $\mathrm{Km}$ of the free one, $110 \mathrm{mM}$; this indicates that the

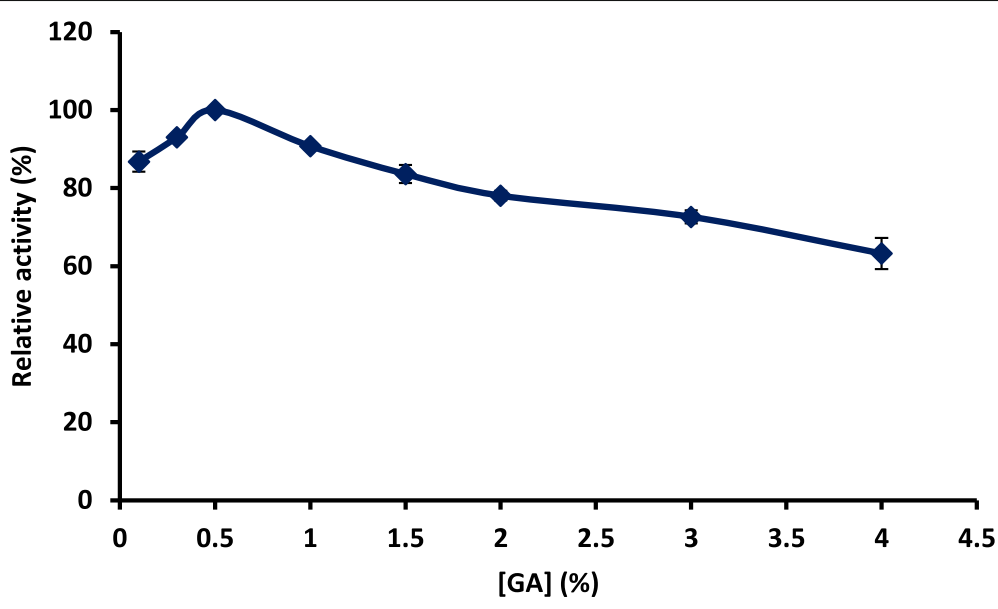

Fig. 5 Effect of variation of GA concentration on the catalytic activity of immobilized enzyme 


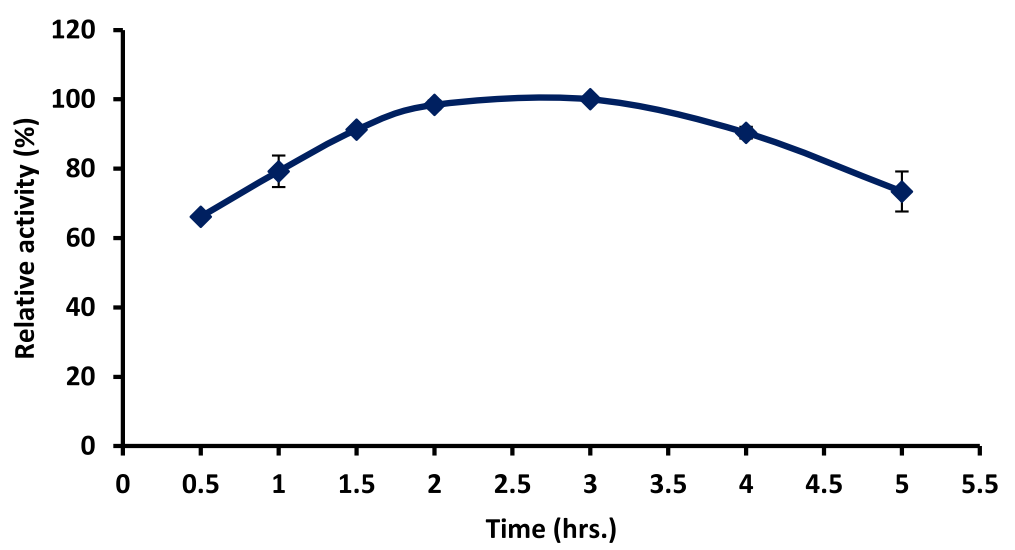

Fig. 6 Effect of variation of GA reaction time on the catalytic activity of immobilized enzyme

immobilized enzyme needs a higher concentration of substrate. On the other hand, the maximum reaction velocity (Vmax) values for the immobilized enzyme were determined; it was found that it decreased from 2.28 to $1.11 \mu \mathrm{mol} \mathrm{min}{ }^{-1}$. These data, higher $\mathrm{Km}$ value with lower Vmax value for covalently immobilized glucoamylase onto spacer-arm attached magnetic poly (methylmethacrylate) microsphers, were in agreement with Arica et al. (2000).

\section{Full conversion}

The relative rate of conversion of the substrate using immobilized enzyme and free one was shown in Fig. 10; we notice that it was higher for the free enzyme than the immobilized one for the first $45 \mathrm{~min}$. After that, both enzyme forms reached their maximum relative conversion rate at around $60 \mathrm{~min}$. The higher activity for the free enzyme compared to the immobilized form for the first 45 min could be regarded to the time required for the immobilized enzyme to retain its better 3D conformation inside the gel beads (Amal et al. 2016).

\section{Reusability}

Reusability is the most important requirement for industrial enzyme applications. The importance of this parameter is because it can evaluate the whole immobilization process. Covalently immobilized glucoamylase reusability was evaluated (Fig. 11). From that figure, we notice that the immobilized enzyme kept its activity (100\%) till 11 successive cycles.

\section{Elucidation of the modified gel beads Fourier-transform infrared spectroscopy}

The FTIR spectroscopic analysis of gel beads in different stages was carried out from 400 to $4000 \mathrm{~cm}^{-1}$ (Fig. 12). IR spectrum of beads showed characteristic peaks (curve A). Spectra for aminated carrageenan beads showed a new broad peak at $3400-3600 \mathrm{~cm}^{-1}$ which was corresponding to $\mathrm{NH}_{2}$ group; this proves that the surface of

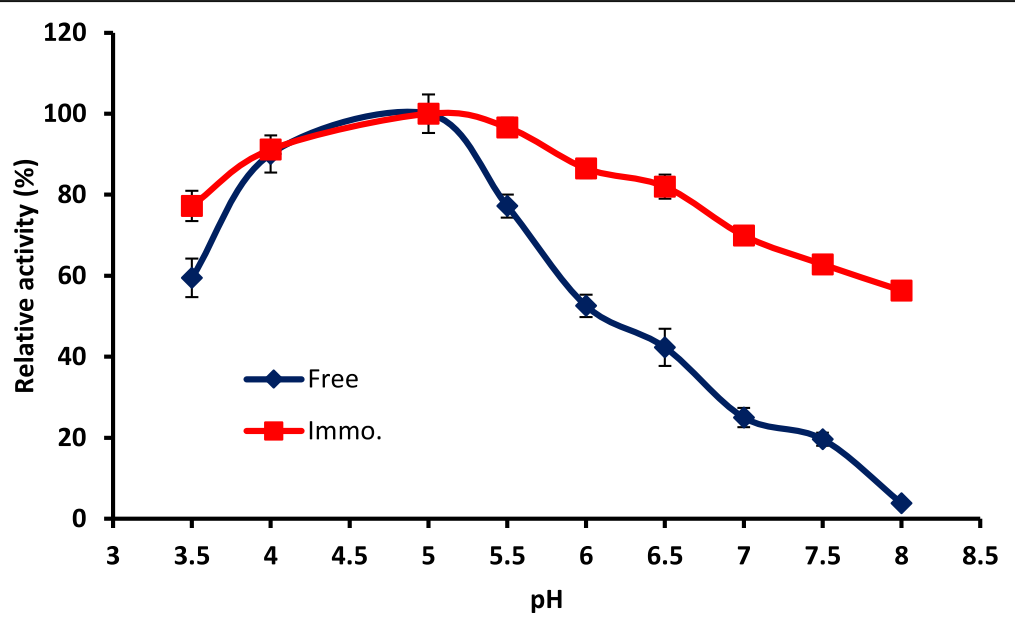

Fig. 7 Optimum pH for free and covalently immobilized glucoamylase enzyme onto activated gel beads 


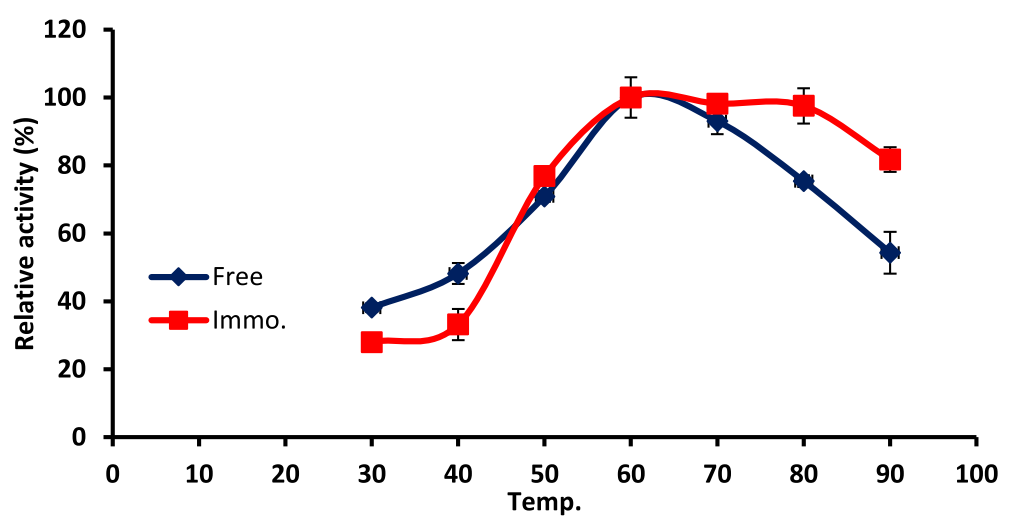

Fig. 8 Optimum temperature for free and covalently immobilized glucoamylase enzyme onto activated gel beads

beads become aminated with an amine group (curve B), while GA-activated beads showed two new peaks. First one was at $1630 \mathrm{~cm}^{-1}$ referred to the $(\mathrm{C}=\mathrm{O})$ group of a free aldehyde end of $\mathrm{GA}$, and another peak is at 1740 $\mathrm{cm}^{-1}$ referring to $(\mathrm{C}=\mathrm{N})$ group which resulted from the reaction of $\mathrm{NH}_{2}$ end groups with $\mathrm{GA}$ aldehyde group (curve C). Finally, immobilized carrageenan beads show a broader peak at $3400-3600 \mathrm{~cm}^{-1}$, referring to the increase in $\mathrm{NH}_{2}$ group's concentration. This increase is due to the enzyme $\mathrm{NH}_{2}$ group (curve $\mathrm{D}$ ).

\section{Scanning electron microscope (SEM)}

Figure 13 displayed SEM for carrageenan, aminated carrageenan, activated carrageenan, and immobilized one. From these curves (A, B, C, and D), we noticed the changes which happened in each step and the accumulation of PEI, GA, and enzymes appear on the surface of the gel beads. As we can see, there is a difference in the surface after each step. From the figure also, we can see the difference in pore size after each step.

\section{Discussion}

For the immobilization of the enzyme on the gel beads, gel beads should be activated first by adding new function groups that interact with the function groups of enzyme. This activation process contains two main subprocesses. Amination step in which the catalytic activity of enzyme increased with the increase of amino groups also increase with increasing amination $\mathrm{pH}$ as reported by Wahba and Hassan (2017). On the other hand, in the activation process, the catalytic activity increased with the increase of GA concentrations up to $0.5 \%$ and tends to decrease. This decrease in activity may be because of the consumption of two aldehyde groups in the reaction with an amino group on the surface of carrageenan gel beads, so the suitable concentration of GA was $0.5 \%(v /$ $v$ ) and it was close to the results reported by Kishore et al. (2012). After the immobilization of glucoamylase enzyme on the $\mathrm{k}$-carrageenan gel beads, the optimum $\mathrm{pH}$ was determined. Although there is no big difference between the optimum $\mathrm{pH}$ between free and immobilized one, the immobilized enzyme shows more stability under

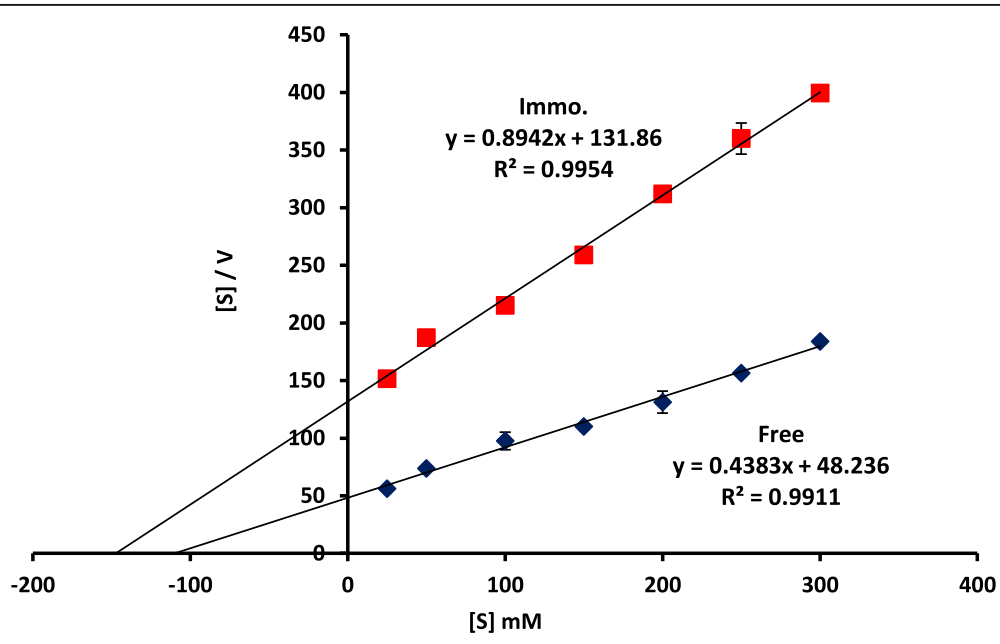

Fig. 9 Kinetic parameters of free and immobilized glucoamylase enzyme using the Hanes-Woolf plot method 


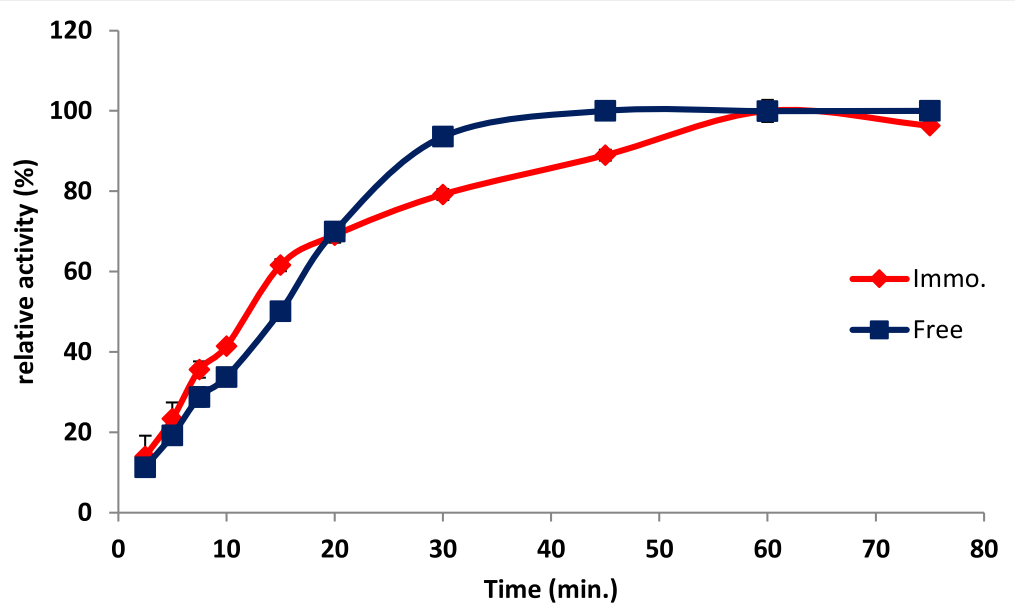

Fig. 10 Full conversion of substrate using free and immobilized glucoamylase enzyme onto activated gel beads

acidic conditions. This $\mathrm{pH}$ stability at the acidic region is well known as the effect of Schiff's base formation, and this is in accordance with other previously published data (Zhou 2010). This behavior of stability may also because of the covalent bond formed between amine groups of enzyme and function groups found on the surface of gel beads. These strong covalent bonds can increase enzyme stability against $\mathrm{pH}$ changes. Tanriseven and Olcer (2008) have the same observation when they immobilized glucoamylase onto polyglutaraldehyde-activated gelatin. And for the optimum temperature, the immobilized enzyme became stable at a wide range of temperatures (about $20^{\circ} \mathrm{C}$ ). This behavior may be because of the formation of a strong covalent bond between enzyme and gel beads.

These data is in agreement with Zifei Dai (2011) who found that the optimum temperature of immobilized glucoamylase is $60^{\circ} \mathrm{C}$. The immobilization could reduce the conformation flexibility of the enzyme, leading to an increase in thermal stability. For the kinetic parameters of the immobilized enzyme, the Km became higher than that of the free one. The increase in $\mathrm{Km}$ value might be because of the diffusional limitations or steric effects that made changes in the reaction ability between the active site of the enzyme and the substrate (Buchholz, 1992).

The most important parameter that evaluates the immobilization process is the reusability of the immobilized enzyme many times. In our case, the immobilized glucoamylase was reused for 11 cycles without any loss of its activity. This is similar to the data reported by Tanriseven and Olcer (2008) who immobilized glucoamylase onto polyglutaraldehyde-activated gelatin by the covalent method and Czichocki et al. (2001) who immobilized the same enzyme into polyelectrolyte matrix using the entrapment method. From characterization steps, FTIR and SEM, it was concluded that the process of amination, activation, and immobilization takes place successfully. This result was in agreement with other published results (Abeer et al. 2017).

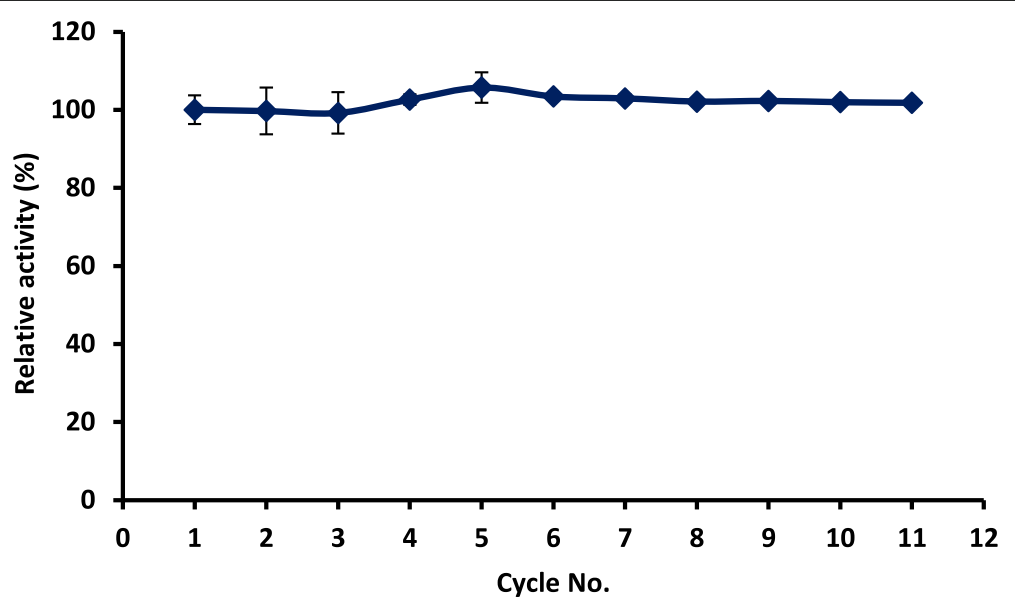

Fig. 11 Operational stability of immobilized glucoamylase enzyme 


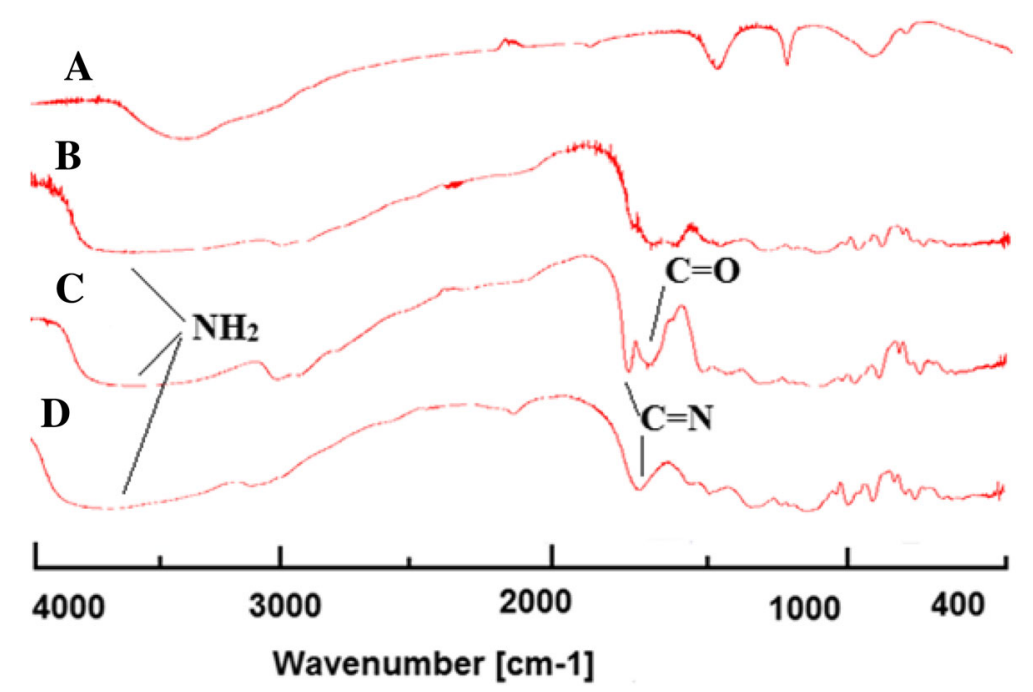

Fig. 12 FTIR for carrageenan (a), aminated carrageenan (b), activated carrageenan (c), and enzyme immobilized on carrageenan (d)

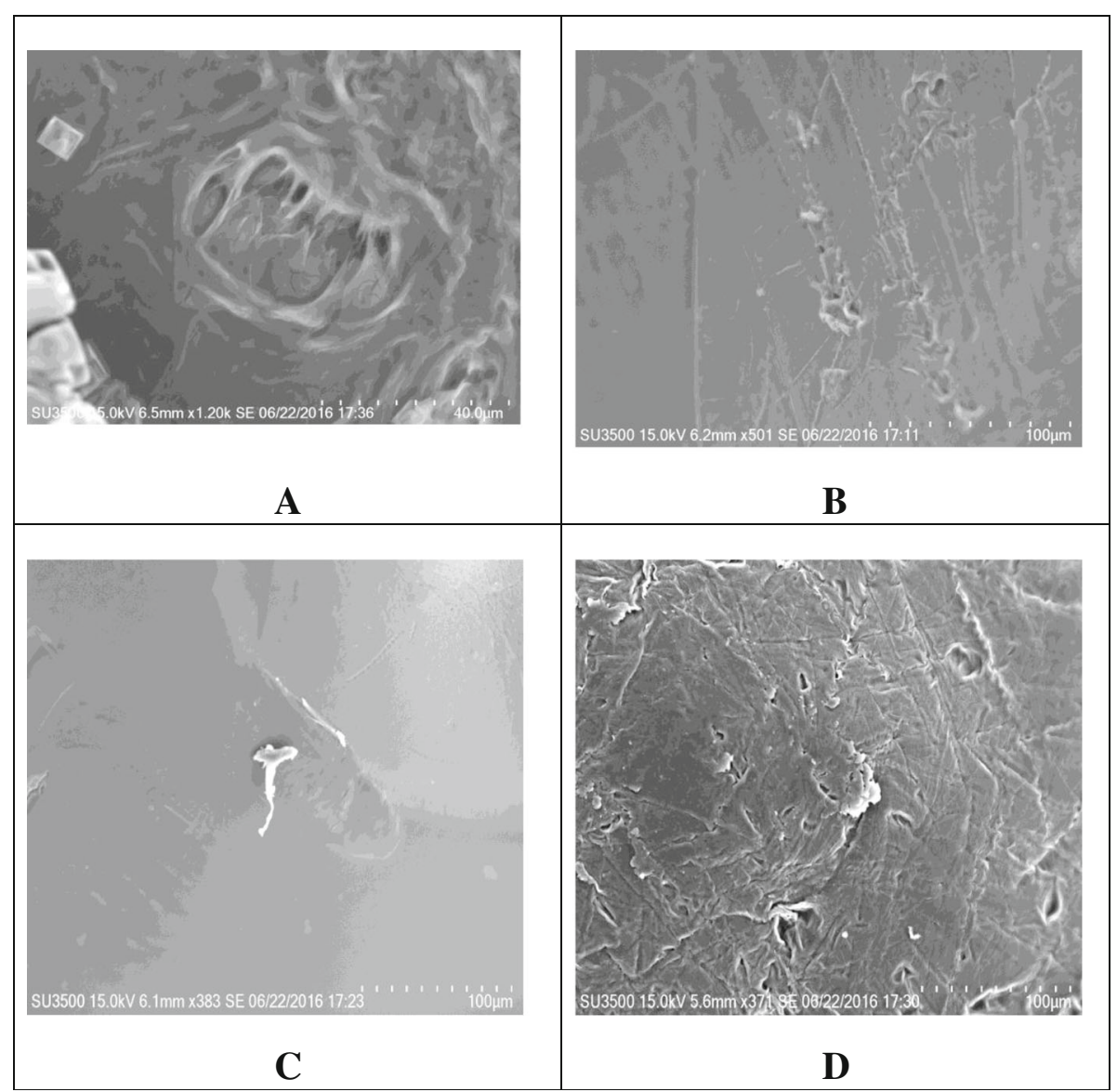

Fig. 13 SEM for carrageenan (a), aminated carrageenan (b), activated carrageenan (c), and enzyme immobilized on carrageenan (d) 


\section{Conclusions}

It could be concluded from the obtained results that glucoamylase enzyme can be immobilized on $\mathrm{K}$-carrageenan gel beads after activation by using polyethylenimine (PEI) followed by glutaraldehyde (GA). The immobilization process improved the enzyme properties such as temperature, $\mathrm{pH}$ to great instance. The immobilized enzyme can be reused for 11 cycles without loss in its activity. The $\mathrm{Km}$ of the immobilized enzyme, $147.46 \mathrm{mM}$, becomes higher than $\mathrm{Km}$ of the free one, $110 \mathrm{mM}$. The maximum reaction velocity (Vmax) values for the immobilized enzyme decreased from 2.28 to $1.11 \mu \mathrm{mol} \mathrm{min}{ }^{-1}$. These results confirm the economic and biotechnical benefits of enzyme immobilization.

\section{Abbreviations}

DNS: Dinitrosalicylic acid; FTIR: Fourier-transform infrared; GA: Glutaraldehyde; KCl: Potassium chloride; Km: The Michaelis constant; PEl: Polyethylenimine; SEM: Scanning electron microscope; Vmax: Maximum reaction velocity

\section{Authors' contributions}

MEH conceived and designed the experiments, performed the experiments, and analyzed the data. MEH, QY, and ZX wrote the paper. All authors read and approved the final manuscript.

\section{Authors' information}

Mohamed E. Hassan is an associate professor in Center of Excellence, Encapsulation \& Nano biotechnology Group, Chemistry of Natural and Microbial Products Department, National Research Centre, El Behouth Street, Cairo 12622, Egypt, and a visiting post-doctoral fellowship in College of Grain Science and Technology, Shenyang Normal University, 253 Huanghe North Street, Huanggu District, Shenyang, 110034 China.

Qingyu Yang is an associate professor in College of Grain Science and Technology, Shenyang Normal University, 253 Huanghe North Street, Huanggu District, Shenyang, 110034 China.

Zhigang Xiao is a professor in College of Grain Science and Technology, Shenyang Normal University, 253 Huanghe North Street, Huanggu District, Shenyang, 110034 China.

\section{Funding}

Not applicable

\section{Availability of data and materials}

All data generated or analyzed during this study are included in this manuscript.

\section{Ethics approval and consent to participate}

Not applicable

\section{Consent for publication}

Not applicable

\section{Competing interests}

The authors declare that they have no competing interests.

\section{Author details}

'College of Grain Science and Technology, Shenyang Normal University, 253 Huanghe North Street, Huanggu District, Shenyang 110034, China. ${ }^{2}$ Center of Excellence, Encapsulation \& Nano biotechnology Group, Chemistry of Natural and Microbial Products Department, National Research Centre, El Behouth Street, Cairo 12622, Egypt.
Received: 27 March 2019 Accepted: 13 June 2019

Published online: 25 June 2019

\section{References}

Abeer AAEA, Faten AM, Mohamed EH, Eman RH, Mona AE (2017) Covalent immobilization of Alternaria tenuissima KM651985 laccase and some applied aspects. Biocatalysis and Agricultural Biotechnology 9:74-81

Alftrén J, Hobley TJ (2013) Covalent immobilization of $\beta$-glucosidase on magnetic particles for lignocellulose hydrolysis. Applied Biochemistry and Biotechnology 169:2076-2087

Amal MH, Esawy MA, Gamal AA, Helal MMI, Hassan ME, Hassanein NM (2016) Enzymatic synthesis using immobilized Enterococcus faecalis Esawy dextransucrase and some applied studies. International Journal of Biological Macromolecules 92:56-62

Arica MY, Handan Y, Patir S, Denizli A (2000) Immobilization of glucoamylase onto spacer-arm attached magnetic poly(methylmethacrylate) microspheres: characterization and application to a continuous flow reactor) Journal of Molecular Catalysis. B, Enzymatic 11:127-138

Bassem M. Salama, Mohamed E. Hassan, Doaa A. R. , Ghada E. A. Awad, Naziha M. Hassanein, Wafaa A. Helmy, Mona A Esawy (2018) Chemical characterization of Levan and optimization of immobilized Bacillus tequilensis levansucrase onto k-Carrageenan-CMC Gel Beads. Egyptian Journal of Chemistry 61(5):857 $-866$

Bezerra CS, de Farias Lemos CMG, de Sousa M, Gonçalves LRB (2015) Enzyme immobilization onto renewable polymeric matrixes: past, present, and future trends. Journal of Applied Polymer Science 132(26):1-15

Buchholz K (1992) Immobilized enzymes: kinetics, efficiency, and applications. International Journal of Chemical Engineering 32:1-13

Coutinho PM, Reilly PJ (1997) Glucoamylase structural, functional and evolutionary relationships. Protein Eng. 29:334-347

Czichocki G, Dautzenberg H, Capan E, Vorlop KD (2001) New and effective entrapment of polyelectrolyte-enzyme-complexes in LentiKats. Biotechnology letters 23(16):1303-1307

Elnashar MMM, Hassan ME, Awad GEA (2013) Grafted carrageenan gel disks and beads with polyethylenimine and glutaraldehyde for covalent immobilization of penicillin G acylase. Journal of Colloid Science and Biotechnology 2(1):27-33

Faber K (2011) Biotransformation in organic chemistry: a textbook, 6th edn. Springer-Verlag, Berlin Heidelberg

Franzreb M, Siemann-Herzberg M, Hobley TJ, Thomas ORT (2006) Protein purification using magnetic adsorbent particles. Applied Microbiology and Biotechnology 70:505-516

Gerhartz W (1990) General production methods. In: Gerhartz W (ed) Enzymes in industry, New York, p 67: VCH)

Girelli AM, Mattei EJ (2005) Application of immobilized enzyme reactor in on-line high performance liquid chromatography: a review. Chromatogr. B Anal. Technol. Biomed. Life Sci. 819:3-16

Ida J, Matsuyama T, Yamamoto H (2000) Immobilization of glucoamylase on ceramic membrane surfaces modified with a new method of treatment utilizing SPCP-CVD. Biochemical Engineering Journal 5:179-182

Kishore D, Talat M, Srivastava ON, Kayastha AM (2012) Immobilization of $\beta$ galactosidase onto functionalized graphene nano-sheets using response surface methodology and its analytical applications. PLoS One 7:1-13

Miller GL (1959) Use of dinitrosalicylic acid reagent for determination of reducing sugar. Anal Chem 31:426-428

Mohamed H, Xiao ku R, Ying Y, Xiaoning L, De-Qiang D (2019) Biotransformation of ginsenoside using covalently immobilized snailase enzyme onto activated carrageenan gel beads. Bull Mater Sci 42:29

Oh JT, Kim JH (2000) Preparation and properties of immobilized amyloglucosidase on nonporous PS/PNaSS microspheres. Enzyme and Microbial Technology 27:356-361

Schultz N, Syldatk C, Franzreb M, Hobley TJ (2007) Integrated processing and multiple re-use of immobilised lipase by magnetic separation technology. Journal of Biotechnology 132:202-208

Sunita A (2019) Application of immobilized enzymes in the food industry, enzymes in food biotechnology, production, applications, and future prospects, pp 711-721

Tanriseven A, Olcer Z (2008) A novel method for the immobilization of glucoamylase onto polyglutaraldehyde-activated gelatin. Biochemical Engineering Journal 39:430-443

Wahba Ml, Hassan ME (2017) Agar-carrageenan hydrogel blend as a carrier for the covalent immobilization of $\beta$-D-galactosidase. Macromol. Res. 25:913 
Wang J, Wu D, Zhao G, Li M, Li Y, Han Y, He A, Jiang Y (2014) Reversible immobilization of glucoamylase onto magnetic polystyrene beads with multifunctional groups. Process Biochemistry 49:845-849

Wang J, Zhao G, Li Y, Liu X, Hou P (2012) Reversible immobilization of glucoamylase onto magnetic chitosan nanocarriers. Applied Microbiology and Biotechnology 97(2):681-692

Ying Y, Xiaoning L, Xiao KR, Mohamed EH, Deqiang D (2016) Covalent immobilization of cellulase in application of biotransformation of ginsenoside Rb1. Journal of Molecular Catalysis B: Enzymatic 133:S525-S532

Zhou J (2010) Immobilization of cellulase on a reversibly soluble-insoluble support: properties and application. Journal of Agricultural and Food Chemistry 58:6741-6746

Zifei Dai (2011) Co-immobilization of thermostable alpha-amylase and glucoamylase for starch hydrolysis. Dissertation for the Degree Doctor of Philosophy in the Graduate School of The Ohio State University 60

\section{Publisher's Note}

Springer Nature remains neutral with regard to jurisdictional claims in published maps and institutional affiliations.

\section{Submit your manuscript to a SpringerOpen ${ }^{\circ}$ journal and benefit from:}

- Convenient online submission

- Rigorous peer review

- Open access: articles freely available online

- High visibility within the field

Retaining the copyright to your article

Submit your next manuscript at $\boldsymbol{\triangleright}$ springeropen.com 